\title{
Guerreiras ou Anjos? As Mulheres Brasileiras e a Grande Guerra
}

\author{
Elaine Pereira Rocha' (iD) 0000-0003-2150-1931 \\ 'University of the West Indies, Cave Hill Campus. Bridgetown, Barbados. \\ BB 11000-history@cavehill.uwi.edu
}

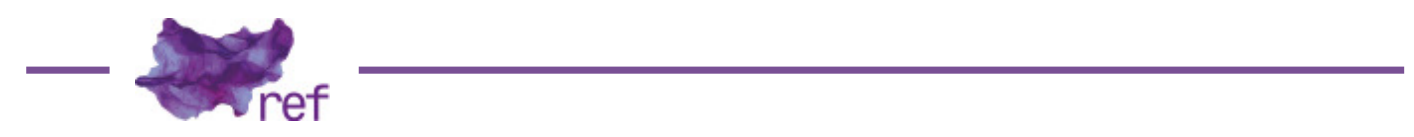

\begin{abstract}
Resumo: A Primeira Guerra Mundial foi um fenômeno de repercussão internacional que ocorreu em meio a inúmeras transformações nos âmbitos econômico, político, social e cultural. Sua repercussão no Brasil aconteceu principalmente a partir de 1917, quando, reagindo a uma agressão direta, o governo declarou guerra à Alemanha. Este artigo reflete os debates sobre a participação das mulheres na Guerra, nas funções de enfermeiras e soldadas. A formação da Legião Feminina da Morte, na Rússia, causou grande impacto ao mostrar ao mundo as imagens de mulheres trajando uniformes militares masculinos e participando em combates diretos. Da mesma forma, o apelo da Cruz Vermelha por voluntárias se transformou num clamor internacional. Em meio a tudo isso, havia ainda a agenda feminista e sufragista e as discussões sobre o papel da mulher na sociedade moderna. Palavras-chave: guerra; feminismo; enfermeiras; soldadas; maternidade.
\end{abstract}

\section{Warriors or Angels? Brazilian Women and the Great War}

Abstract: The First World War had great repercussion worldwide, having occurred in the midst of numerous transformations in the economic, political, social and cultural spheres. The impact in Brazil happened mainly from 1917, when Brazil was directly assaulted by Germany and declared war to that country. This article reflects the debates about female participation in the War, whether as supporters, nurses or soldiers. The formation of the Women's Legion of Death in Russia has made a major impact by showing the world the images of women in military uniforms and fighting in the battlefield. In the same way the appeal of the Red Cross by volunteers became an international clamor. In addition, there were the feminist and suffragist agenda and the discussions on the role of women in modern society.

Keywords: War; Feminism; Nurses; Female Soldiers; Motherhood.

\section{Entre Cuidar e Matar}

Entre outubro e dezembro de 1917, os habitantes do Rio de Janeiro que passavam pelo centro da capital eram surpreendidos pela presença de mulheres jovens se comportando de uma maneira que contradizia as normas de uma sociedade marcadamente patriarcal: vestidas com uniformes militares e portando armas e espadas, elas realizavam exercícios militares no meio do Campo de Santana, sob a supervisão de um oficial aposentado e de Leolinda de Figueiredo Daltro, diretora da Escola de Sciências Artes e Profissões Orsina da Fonseca para estudantes do sexo feminino. Em sua edição de 11 de novembro de 1917, o popular jornal carioca $A$ Noite publicou uma foto das jovens em sua primeira página, com uma breve explicação: as estudantes eram membros do Partido Republicano Feminino, fundado por Leolinda Daltro, e a escola da professora tinha sua própria linha de tiro, onde as alunas também aprendiam esgrima e outras artes militares (A NOITE, 1917a, p. 1). O jornal ressaltava ainda o fato de que a professora Daltro estava oferecendo ao governo federal os serviços de suas alunas como uma força policial para manter a ordem na cidade, caso o Exército regular fosse enviado ao estrangeiro para servir na Grande Guerra.

Aquele não foi o único grupo de brasileiras a aparecer na mídia escrita preparando-se para a Guerra. As voluntárias da Cruz Vermelha também usaram espaços públicos para fazer 
exercícios de simulação de resgate e administração de primeiros socorros a soldados feridos em campos de batalha de uma guerra imaginária.

A opinião pública se dividiu em reação às reportagens sobre enfermeiras laicas, que também estavam na Revista Careta, Revista Cigarra, e em vários jornais, como o Jornal do Brasil e o Correio Paulistano. Conservadores e conservadoras criticavam a ideia, ressaltando que as enfermeiras corriam risco moral em hospitais (e nos campos de batalha), pela proximidade com homens, muitas vezes desnudos, enquanto os progressistas acolheram com entusiasmo o engajamento das mulheres e essa extensão do cuidado materno ao chamado cívico do Estado.

As imagens de jovens enfermeiras e soldadas circularam por jornais de vários países, acirrando os debates sobre a guerra, sendo que as mulheres em uniforme militar evocaram reações mais fortes do que as enfermeiras. Afinal, mesmo que as enfermeiras se colocassem sob o risco de moral - um risco maior para jovens solteiras, especulando-se que estas poderiam também arriscarse a avanços sexuais dos soldados -, elas ao menos estariam fazendo algo inerente ao seu gênero, isto é: cuidando do homem ferido (Elizete PASSOS, 2012). Já as mulheres armadas para exercícios militares encarnavam a antítese da imagem feminina, visto que a função primordial dos soldados é matar o inimigo. Temos, portanto, duas imagens paradoxais da mulher: uma que se esforça para manter a vida, atuando no papel de enfermeira, e outra que se dispunha a ir para os campos de batalha para matar.

Enquanto jornais e revistas brasileiras acompanhavam a Grande Guerra e retratavam as enfermeiras estrangeiras da Cruz Vermelha, vestidas com o hábito branco marcado pela cruz e salvando vidas nos campos de batalha da Europa, alguns aproveitaram e adaptaram a novidade como fantasias para o carnaval no Rio de Janeiro. Assim, em 1916 e 1917 as vestes estilizadas de enfermeiras ganharam espaço na folia, prova da popularização do debate nacional sobre a presença das mulheres na guerra, e uma amostra do humor típico brasileiro (Fernando PORTO; Anna ATAIDE; Débora VILELLA; Marina RIBEIRO, 2014). Quanto às soldadas, ainda que a ideia causasse repúdio à maioria, a indústria da moda passou a criar vestidos e casacos inspirados nos uniformes masculinos, que ilustravam as páginas dedicadas à moda e, consequentemente, os anúncios das lojas voltadas ao público feminino, em diversos jornais do período, fenômeno que se repetiu durante a Segunda Guerra Mundial.

No cerne do debate estava a imagem da mulher, historicamente associada à fragilidade física, à passividade, antagônica à violência, conforme moldada pela cultura patriarcal e reforçada pelas tradições católicas, como o culto da Virgem Maria. A imagem da "mãe sacrificial", obediente e dedicada à família foi herdada da Igreja medieval e introduzida nas Américas desde a colonização, sendo especialmente valorizada entre a segunda metade do século XIX e a Primeira Guerra Mundial.

Dois fatores contribuíram para que a imagem da mulher-mãe, cuidadora e gentil ganhasse força na América Latina: a influência dos pensadores positivistas e românticos, que destacam a importância da mulher como mãe-educadora, responsável pelos novos cidadãos (seus filhos) e apoiadora do marido; e o direcionamento do Vaticano, evidenciado no Dogma da Imaculada Conceição. Este, lançado em 1854, reforça o dogma de que Maria concebeu Jesus sem contato sexual, sendo a mãe virginal do Cristo e o modelo a ser seguido pelas mulheres católicas (Raquel LIMA; Igor TEIXEIRA, 2008; Elisabeth BADINTER, 1985).

\section{Maternidade, Romantismo, Patriotismo}

A ênfase católica na mulher-mãe e na santidade da maternidade precisa ser compreendida como uma ideologia voltada primordialmente à mulher branca, pertencente às camadas média e superior da sociedade. Mulheres pobres, escravizadas ou livres, em geral não eram alvo do mesmo discurso. Neste caso, o abandono, a exploração sexual das mulheres, a ausência da figura paterna e a separação das famílias eram consideradas como parte das dinâmicas de classe, naturalizadas pela sociedade (Rachel SOIHET, 1989; Claudia FONSECA, 1997; Elaine ROCHA 2002).

Já a atuação das mulheres nos campos de batalha tem despertado grande interesse, principalmente nas grandes guerras ocorridas a partir do século XVIII, tais como a Guerra de Independência dos Estados Unidos e a Guerra de Secessão Americana, onde desempenharam múltiplos papéis (Jane SCHULTZ, 2007). A partir das Guerras de Independência, no século XIX, a presença de mulheres nos campos de batalha tornou-se uma constante na historiografia das Américas. Um dos mais notáveis exemplos é o das soldaderas do México: mulheres envolvidas diretamente nas guerras desde as lutas pela independência até a Revolução Mexicana, reconhecidas pelas autoridades federais e respeitadas nos campos de batalha. Segundo estudos, muitas dessas mulheres decidiram pegar em armas após a morte de seus maridos, pais ou irmãos, para defender-se contra roubos e estupros. Algumas desempenharam papéis múltiplos durante as guerras: foram cozinheiras, lavadeiras, enfermeiras, prostitutas, espiãs e soldadas (Elizabeth SALAS, 1990). No Brasil, documentos oficiais da Guerra do Paraguai relatam a presença de mulheres pobres que acompanhavam seus familiares nos campos de batalha, ou que, vivendo nas áreas 
de combates, juntavam-se às barracas para trabalharem como enfermeiras, cozinheiras ou lavadeiras (Maria Teresa DOURADO, 2010; ROCHA, 2002).

Mas foi nas últimas décadas do século XIX que o debate sobre o papel das mulheres na sociedade e na construção da nação tomou um peso maior, figurando na imprensa informativa e nos romances. Parte disso foi a propagação do ensino para mulheres, que começou a tomar corpo neste período, e o desenvolvimento da imprensa no Brasil, eventos que aconteceram simultaneamente e em consequência da divulgação das ideias românticas, do positivismo, e da proposta modernizadora (Dulcília BUITONI, 1981).

Naquele período, enquanto a classe média crescia junto com as cidades e a República nascente demandava investimentos na educação pública para atender às transformações econômicas e ao movimento modernizador, um crescente número de mulheres educadas em seus lares ou em colégios dirigidos por freiras assumia a tarefa de professora, algumas em suas próprias casas, às vezes em troca de pagamento, outras por generosidade. Aquelas que viviam nas cidades apresentaram-se para lecionar nas escolas públicas e particulares, que vinham sendo criadas desde os últimos anos do Império, em troca de salário (Etelvina TRINDADE, 1996; ROCHA, 2016).

O primeiro desafio ao romantismo positivista no Brasil deu-se quando as professoras passaram a exigir pagamento por seu trabalho, contrariando a crença de que educar na escola fosse uma extensão do papel maternal de educar em casa - e, portanto, deveria ser um ato de amor, exercido com o coração, por pura generosidade. Durante os primeiros anos da República, professoras do Rio de Janeiro enviavam ofícios e requerimentos ao governo reivindicando seus salários, sob o argumento de que precisavam sustentar seus filhos (ROCHA, 2002; 2016).

O argumento da responsabilidade maternal, utilizado para obter pagamento por seu trabalho, somou-se ao argumento da cidadã educadora, quando outras batalhas foram travadas no campo da educação, como quando argumentaram por melhor educação para as professoras, para que pudessem educar melhor os futuros cidadãos do país. Isto era importante porque o acesso de mulheres a certas disciplinas, como química e cálculo, era negado. Com o crescimento urbano e a expansão comercial e industrial, muitos homens encontraram melhores oportunidades de emprego, abandonando a área de ensino; adicionalmente, as demandas do mercado de trabalho e os planos de desenvolvimento levaram o governo a investir na ampliação da rede escolar pública nas principais cidades do país. Essa conjunção de fatores permitiu que mais mulheres se empregassem como professoras (TRINDADE, 1996).

O acesso à educação e ao magistério intensificou o contato das mulheres com as questões políticas do país, algo estimulado pelo discurso positivista que ressaltava a educação cívica. Não demorou para que as brasileiras passassem a se utilizar de elementos dessa ideologia para reforçar sua reivindicação do direito ao voto (ROCHA, 2002).

\section{A Guerra exacerbando Ânimos}

A Primeira Guerra Mundial foi a primeira experiência de guerra total vivida pelo mundo, quando países de todos os continentes se viram envolvidos em conflitos militares. Com novas armas e estratégias, estima-se que mais de oito milhões e meio de soldados tenham morrido em consequência da guerra, e que o número de feridos, desaparecidos e prisioneiros tenha chegado perto de 38 milhões de pessoas, incluindo civis (Nadege MOUGEL, 2011). Tais números, aliados à sua larga extensão e longa duração, causou impacto mundial em diversas esferas da vida humana.

Os efeitos social e econômico da guerra eram claramente percebidos a partir de seu terceiro ano. Na Europa e no norte da África, a grande maioria da população masculina em idade ativa entre 16 e 50 anos de idade - foi convocada para o serviço militar. Um dos primeiros efeitos da Guerra sobre a população feminina foi a abertura de novos postos de trabalho, e a convocação das mulheres para que atuassem em campos profissionais antes exclusivamente masculinos. O segundo efeito da prolongação da guerra foi a dificuldade em manter os soldados nos campos de batalha e de substituir aqueles que caíam em combate ou pelas precárias condições impostas pela escassez de recursos, falta de higiene e condições climáticas e ambientais (Gerald J. MEYER, 2006).

A Rússia enviou cerca de 12 milhões de soldados para os campos de batalha, só perdendo em números para a Alemanha. A partir de 1916, o Império Russo, que neste período enfrentava graves problemas internos, passou a encontrar dificuldade cada vez maior para manter os soldados engajados. As baixas - estima-se que o número total de mortos, feridos e aprisionados tenha ultrapassado nove milhões - alimentaram o discurso antiguerra dos bolcheviques que a denunciavam como estratégia capitalista. Quando as russas começaram a pleitear o alistamento de mulheres como parte das forças armadas, o governo russo concordou, utilizando o fato como estratégia para pressionar os homens para lutar.

No dia 21 de junho de 1917, os residentes de Petrogrado assistiram, admirados, a uma parada militar diferente: 300 mulheres vestidas em uniforme militar, portando rifles e com cabelos quase raspados marcharam do quartel para a Catedral de São Isaac, com o apoio de oficiais do Alto Comando do Exército Czarista, de dois bispos e de uma dúzia de padres da lgreja Ortodoxa. 
Era a oficialização do batalhão feminino, que recebeu o nome de Women's Battalion of Death (Melissa STOCKDALE, 2004), conhecido no Brasil como a "Legião Feminina da Morte".

As notícias do batalhão russo feminino e as fotos das soldadas apareceram em jornais de diversas partes do mundo, com grande repercussão nos Estados Unidos, Canadá, França, Inglaterra e Brasil. No Canadá e nos Estados Unidos, mulheres tentaram imitar o exemplo das russas (Lauren HANSEN, 2017), mas muitos críticos referiam-se ao fato como algo antinatural. Tradicionalmente, à parte do papel de enfermeira, a sociedade esperava que as mulheres mantivessem uma postura passiva, fosse na espera pelo ente querido envolvido nas linhas de combate, fosse no luto pelos caídos em batalha e, sobretudo, ao se conformarem com as agruras dos tempos de guerra.

Por outro lado, conforme lembrado por Jean Elshtain (1990), a guerra é o que transforma o homem no cidadão, algo presente nos escritos de Maquiavel e reforçado na proposta da Revolução Francesa do cidadão-soldado. Nesse período, o discurso utilizado para o alistamento militar baseou-se no compromisso cívico que o homem tem para com a defesa da pátria e da família. A masculinização da guerra e do sentimento pátrio também foi verificada por estudiosos de outros conflitos bélicos, conforme aponta Joanne Meyerowitz (2008). No caso da Primeira Guerra, algumas mulheres, que vinham lutando pelo direito à plena cidadania, encaravam sua exclusão dos campos de batalha como uma forma de marginalidade.

Na Rússia, um número impreciso de mulheres - sobretudo estudantes ginasiais e professoras - já vinha participando da guerra como soldadas, sob o disfarce de trajes masculinos e, muitas vezes, com a conivência de soldados, que resguardavam seu segredo (Susan SOWERS, 2003). Essas mulheres atendiam ao apelo patriótico do governo czarista, que convocava cidadãos para a defesa do grande império russo, ameaçado pelas tropas alemãs. À medida que a Alemanha avançava e se fortalecia, esse apelo crescia; um desses marcos foi a vitória parcial desta sobre as forças russas, em julho de 1915, causando a perda da Polônia e da Lituânia. Em reação a tal derrota, o Czar assumiu a liderança do exército russo enquanto os socialistas incrementaram a campanha contra a guerra, que chamavam imperialista. Em 1917, por meio de um panfleto, o governo russo convocou as mulheres para se alistarem para a guerra, deixando bastante explícita a natureza dessa participação:

Cidadãs! Nesta hora terrível, quando as nuvens escuras de anarquia, derrota e colapso econômico estão se acumulando sobre nossa pátria, quando a morte é anunciada para ela, nós, mulheres cidadãs com direitos iguais, somos obrigadas a levantar nossas vozes, somos obrigadas a nos unir e utilizar cada nervo do nosso corpo para voluntariar. A imperativa responsabilidade e o dever cívico convidam a mulher russa a apoiar nosso exército em união e vontade, para fortalecer o espírito de nossas tropas que se abate [e], alistando-se em suas fileiras como voluntárias, transformar as frentes passivas, em frentes ativas e agressivas! (STOCKDALE, 2004, p. 92). ${ }^{1}$

O panfleto acima foi uma das ferramentas pelo alistamento de mulheres. Contou com apoio de setores do governo e dos meios militares, que abraçaram a proposta como uma forma de pressionar os homens a se alistarem e a se manterem nos campos de batalha, sob o risco de serem envergonhados pela valentia do "sexo frágil".

A entrada de mulheres como membros ativos do exército suscitou forte oposição na Rússia, principalmente por dois fatores: o discurso dos bolcheviques que consideravam o ato uma traição para com o povo russo, que deveria se recusar a lutar na guerra imperialista; e a rejeição à soldada, como uma grande transgressão das normas de gênero.

Segundo Pierre Bourdieu (2016), esta seria mais uma situação paradoxal, uma vez que os papéis de gênero tradicionalmente concebidos na bipolaridade masculino/feminino tinham como princípio a subordinação e o controle do sexo feminino, sendo reforçados por instituições como a escola, a Igreja e o Estado de forma mais pungente do que no meio familiar. Tal raciocínio, aplicado à análise dos papéis das mulheres na guerra, não contraria a proposta original de Joan Scott (1986), que defende a análise de gênero para entender a subjetividade na construção dos papéis, neste caso, de homens e mulheres, para melhor examinar relacionamentos marcados pela misoginia e pelo patriarcado. Neste sentido, a história das mulheres se vale do referencial metodológico da história de gênero para trabalhar os processos de construção e de negação dos papéis sociais e políticos atribuídos a homens e mulheres.

O apoio do Estado czarista e da Igreja Ortodoxa ao exército feminino, e o recrutamento de estudantes e professoras, contrariava a norma patriarcal, podendo ser vista como uma medida circunstancial e de exceção, dada a urgência em se reforçar o contingente militar russo.

Sowers (2003), porém, explica que as circunstâncias em que as russas viviam entre 1914 e 1917 eram muito diferentes daquelas vividas por mulheres em lugares mais urbanizados e desenvolvidos - como a Inglaterra, França e mesmo os Estados Unidos da América. Especialmente nas áreas rurais, onde a maioria da população russa se concentrava, enfrentando a vida árdua

\footnotetext{
${ }^{1}$ Tradução da autora, a partir da tradução inglesa de Stockdale.
} 
dos longos invernos e do trabalho duro executado com ferramentas rústicas, a luta diária e circunstâncias comuns como a morte, doença ou a ausência - temporária ou definitiva - do braço masculino exigia que mulheres assumissem tarefas consideradas masculinas, sem que isso fosse considerado transgressão de gênero.

Contudo, havia ainda a oposição de grande parte da sociedade, a qual se refletia entre as fileiras do exército. Stockdale (2004) nos conta que a oficial Maria Bochkareva exigia que as mulheres em seu batalhão usassem cabelos muito curtos, abdicassem de qualquer tipo de maquiagem ou ornamento e, acima de tudo, controlassem sua feminilidade. Ao agir deste modo, a comandante reivindicava, para si e para suas recrutas, a autoridade e o pertencimento num meio predominantemente masculino. Bochkareva também estimulava suas recrutas a xingarem e a cuspirem como homens. Essa aparente masculinização era uma estratégia para que o gênero não fosse um elemento divisório nas linhas de combate, evitando a discriminação, prevenindo abusos e a transgressão dos rígidos códigos morais.

A biografia de Maria Bochkareva revela uma dicotomia entre a condição feminina na Rússia do início do século XX e as representações sobre a soldada. De acordo com Angela Shpolberg (2018), Maria vinha de uma família muito pobre, e seu pai, que havia sido sargento no exército czarista, era extremamente abusivo. Para escapar dele, Maria casou-se aos 15 anos, e logo se descobriu nas mãos de um marido também abusivo, que ela abandonou em pouco tempo, enfrentando grandes obstáculos, sobretudo a miséria. Tempos depois, teria encontrado outro companheiro, que num acesso de ciúme, tentou enforcá-la. Nessa época, já em 1915, a Rússia estava envolvida em diferentes conflitos: a guerra contra a Alemanha, e os conflitos internos entre os bolcheviques e o exército czarista. O governo fazia apelos por mais voluntários para o exército, enquanto os rebeldes ampliavam as campanhas contra a guerra imperialista e por mais soldados revolucionários. Maria decidiu alistar-se no exército do Czar. Ela cortou os cabelos muito curtos, adotou o nome masculino de Yashka, vestiu uniforme militar e assumiu posto nas frentes de combate. A transgressão de gênero, neste caso, foi uma estratégia para vencer sua condição de vítima.

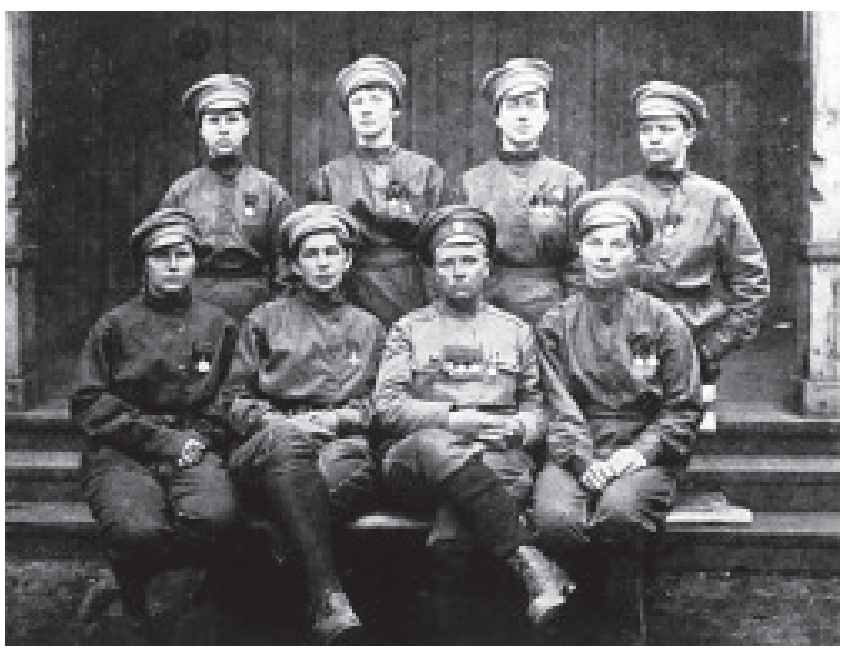

Figura 1. Soldadas do Batalhão Feminino da Morte

O caso da Rússia chama atenção por ter sido o único no qual um batalhão de mulheres participou ativamente da Guerra e teve soldadas incorporadas a outros batalhões nas fileiras de combate. Outros países também estenderam às mulheres o apelo da Guerra. Em fevereiro de 1917, a Inglaterra criou o Women's Army Auxiliary Corps que, em abril do ano seguinte, se tornou o Queen Mary's Army Auxiliary Corps (Francesca MORSELLI; Jörg LEHMAN, 2016), cuja principal função, como o próprio nome diz, era dar apoio ao exército regular (dos homens). Mulheres eram recrutadas para assumir tarefas em escritórios, cantinas, na área de transportes (como motoristas de veículos militares e ambulâncias), nos armazéns de munição, no controle de materiais e até mesmo nas oficinas, como mecânicas de manutenção. O propósito de sua participação era liberar homens para as frentes de combate. Diferente de mulheres de outras nacionalidades, as britânicas receberam soldo e foram reconhecidas como parte da força militar oficial.

A incorporação desse contingente feminino ao exército britânico seguia normas rígidas, tanto no que se referia ao vigor físico quanto na demonstração de habilidades específicas: saber dirigir automóveis, saber datilografia, dominar um idioma estrangeiro, por exemplo. Muitas mulheres de classe média, com bom nível de educação, foram atraídas para a corporação. Ao final da guerra, em 1918, mais de 50 mil inglesas haviam sido voluntárias no Exército, na Marinha, e mesmo na Força Aérea, sendo que muitas delas tinham atuado nas frentes de batalha na França, Bélgica, Itália e Grécia, mas não em combate (MORSELLI; LEHMAN, 2016). 
Nos Estados Unidos surgiram corporações femininas em diferentes estados, seguindo o modelo inglês. Mais de 13 mil mulheres alistaram-se na Marinha, algumas foram incorporadas à Guarda Costeira e muitas acompanharam as forças americanas nos campos de batalha na Europa (MORSELLI; LEHMAN, 2016). Mulheres do estado de Massachusetts formaram seu próprio Batalhão da Morte, em 1917 (HANSEN, 2017). Isso sem falar no grande número de mulheres jornalistas que acompanharam a movimentação de guerra em diferentes lugares e contribuíram para dar visibilidade à participação feminina.

A imprensa brasileira publicou notícias esparsas sobre mulheres nas frentes de batalha. Em dezembro de 1917, a Revista Feminina publicou uma notícia sobre o Exército Feminino na Inglaterra, ressaltando diferenças de classes entre as voluntárias:

O exército feminino, cifrando-se em um milhão, não é para se desprezar em tempo de guerra, e sobretudo quando representa o quinto do novo exército britânico. Os chefes do governo dirigiram às mulheres em outubro de 1916, o aviso seguinte:

"O ministro das munições está prompto a receber todos os pedidos de mulheres, de todas as classes, desejando entrar como aprendizes de munições nos centros que o ministério formou nas diversas partes do reino."

As mulheres responderam em massa ao chamado.

Ellas deram quase sem preparação um esforço superior ao dos operários antes da guerra e isto por um salário muito menos elevado. As vigilantes pertencem quase sempre a uma classe superior. As obreiras obedecem de boa vontade à aristocracia que sabe dirigir: respeitam-n'a e escutam-n'a (REVISTA FEMININA, 1917a, p. 56).

Longe das grandes manchetes, essa notícia ocupou apenas um sexto de uma das páginas finais, dedicada ao público feminino, entre receitas culinárias, dicas para enfeitar árvores de natal, conselhos de higiene e um comentário sobre uma nova tendência na cerimônia de casamento. Contudo, passou a fazer parte do anedotário nacional, figurando também em caricaturas de jornais, que mostravam as mulheres chegando atrasadas para o front porque haviam passado muito tempo retocando a maquiagem, por exemplo.

Já as notícias sobre a Guerra contra a Alemanha e seus aliados apareciam cada vez mais nos jornais, principalmente após o primeiro ataque dos alemães a navios brasileiros, ocorrido em maio de 1917. Durante o debate sobre a posição do Brasil no conflito mundial, intelectuais de renome como Olavo Bilac e Rui Barbosa ocuparam as páginas de jornais para defender uma participação ativa do país no conflito (Ranielle LEAL; Ana REGO, 2015).

Nesse mesmo período, o Brasil vivenciava o desenvolvimento da campanha sufragista, influenciado por eventos da Europa, apesar da luta das mulheres brasileiras por direitos se anteceder à "onda sufragista", conforme June Hahner (1981) demonstrou. A professora Leolinda Daltro, que vinha reivindicando não apenas o direito ao voto como eleitora, mas como potencial candidata, fazia campanha pelo voto e aliciava as alunas de sua escola e outras senhoras para o movimento (ROCHA, 2002).

Quando decidiu formar o batalhão feminino, a professora Daltro encontrou apoio entre alguns militares aposentados, que se dispuseram a ajudar nos treinos de esgrima, tiro e táticas de combate. Mas as manobras no centro da cidade encontraram oposição e foram ridicularizadas na imprensa, servindo como uma grande distração, naquele momento em que os brasileiros debatiam a participação na Guerra. Professora e alunas eram insultadas por homens que se reuniram para observá-las, tornando-se assunto de piadas e anedotas em jornais e até peças de teatro. Questionada por um jornalista sobre suas motivações ao incentivar as jovens a se comportarem dessa maneira transgressora, a professora disse agir impulsionada pelo dever patriótico (Leolinda DALTRO, 1922).

O debate sobre a guerra apresentou para feministas ${ }^{2}$ uma nova oportunidade de defender publicamente ideias sobre a igualdade de gênero e a mulher como cidadã. Sabiamente, a professora diversificou sua proposta de participação das mulheres nos esforços de guerra, ao incluir o treinamento para enfermeiras no programa de sua escola, obtendo maior apoio público.

\section{O Brasil e a Guerra}

As relações externas e a situação interna do Brasil eram complexas na virada do século XX. A República nascente lutava para estabilizar o país e conquistar o reconhecimento como uma nação moderna. Havia forte preocupação com as fronteiras com a Bolívia, Paraguai, Peru e Guianas, bem como com os investimentos internacionais e os acordos comerciais firmados entre 1890 e 1910. O Estado tinha boas razões para construir fortes, ampliar as forças militares e navais, e estabelecer um efetivo corpo diplomático (José Murilo CARVALHO, 1997; Valterian BRAGA, 2008).

\footnotetext{
${ }^{2}$ O uso do termo "feminista" passou a ser utilizado oficialmente no Brasil em 1922, contudo, não se pode chamar o movimento das mulheres das primeiras décadas do século XX de sufragista, devido ao risco de se limitar a importância de suas reivindicações, que iam além do direito de voto, abrangendo o acesso à educação, emprego e outros direitos civis.
} 
Inicialmente, o conflito trouxe algum benefício comercial ao Brasil, pois as exportações de cacau, açúcar e café aumentaram em 1915 e 1916 para atender às demandas das tropas na zona de guerra. Gradualmente, porém, as perturbações do comércio transatlântico afetaram a economia. O Brasil perdeu importantes parceiros comerciais, como a Alemanha e a Escandinávia, particularmente quando a Grã-Bretanha confiscou cargas brasileiras como parte de seu bloqueio às potências centrais.

Em janeiro de 1917, o Brasil protestou contra os custos comerciais do bloqueio das potências aliadas pela Alemanha. Poucos meses depois, em abril, um submarino alemão afundou um cargueiro brasileiro no Atlântico em circunstâncias que não foram imediatamente esclarecidas. Mais três cargueiros foram afundados nos meses seguintes. A essa altura, os Estados Unidos declararam guerra à Alemanha e começaram a pressionar o Brasil a fazer o mesmo. Em junho, o Brasil rompeu relações diplomáticas com a Alemanha e permitiu que as forças navais aliadas usassem os portos brasileiros (BRAGA, 2008).

Contudo, o afundamento dos cargueiros não foi suficiente para fazer o Brasil entrar na guerra. As relações econômicas do Brasil com as potências aliadas incluíam uma longa história de modernos projetos de infraestrutura, como sistemas ferroviários e instalações portuárias, os quais envolviam pesados investimentos de capital britânico, americano e canadense. A grande dependência financeira tornou o país vulnerável aos apelos diplomáticos, e o Brasil se juntou aos Aliados (BRAGA, 2008).

Os primeiros anos da República foram marcados pela militarização. Em 1896, o governo criou a Confederação Brasileira de Tiro, com o objetivo de aumentar o interesse de jovens da classe média e alta pela vida militar. A iniciativa não teve muito sucesso e foi revisitada em 1906 e 1908, quando o projeto nacional para o Exército foi reforçado por lei federal e a instrução militar passou a fazer parte do currículo nacional das escolas secundárias para rapazes. A campanha pelo serviço militar contou com o apoio de intelectuais militares, que enfatizavam sentimentos nacionalistas em escritos de jornais, livros didáticos e até mesmo em romances escritos com a intenção de influenciar a opinião popular. Em 1909, o Brasil tinha mais de 50 "clubes de tiro" organizados privadamente, com mais de 13.500 membros (CARVALHO, 1997).

A Guerra viria a reacender tal interesse. Intelectuais e políticos criaram a Liga Brasileira Pelos Aliados em 1915 para fazer campanha contra a posição oficial de neutralidade, nos jornais mais importantes da época (Livia CLARO, 2014). Notícias da Guerra chegavam diariamente da Europa e faziam parte das conversas e leitura de pessoas instruídas. A imprensa brasileira reimprimia com frequência notícias sobre o progresso da guerra dos jornais estrangeiros. Noticiários como: Jornal do Brasil, A Noite, A Gazeta de Notícias, O País e Jornal do Commercio; e semanários como FonFon, A Cigarra, Revista Semanal e Revista Feminina, dentre outros, dedicaram várias páginas à Guerra, a partir de 1916.

Os Clubes e as Linhas de Tiro aumentaram nas cidades por todo o país. Homens foram chamados para se alistar no Exército e listas de voluntários eram entregues aos representantes do governo com grande publicidade. Houve apelos para que mulheres apoiassem o movimento confeccionando uniformes para voluntários pobres (A NOITE, 1917b, p. 1). Para muitos brasileiros, a campanha pela participação na Guerra equivalia a ficar lado a lado com as nações modernas e ser reconhecido como uma delas. Finalmente, em 27 de outubro de 1917, vários jornais brasileiros publicaram o decreto federal que oficializou a entrada do país na Guerra.

Dias depois, na primeira página do jornal $A$ Noite, lia-se: "O QUE OS BRASILEIROS DEVEM FAZER EM TODO O PAIZ: 1) FORMAR LINHAS DE TIRO; 2) ALISTAR-SE NAS LINHAS DE TIRO!" (A NOITE, 1917 c, p. 1). Na mesma matéria, o Ministro das Relações Exteriores Nilo Peçanha afirmava que "[...] Nenhuma manifestação, porém, afirmaria tanto o nosso dever de civilização de povo brasileiro, que a fundação de linhas de tiro em todos os municípios do Brasil" (Idem), enfatizando a necessidade de se organizar e aperfeiçoar as forças de defesa do país. Poucos dias depois, o mesmo jornal exibia na página de assuntos gerais, entre notícias do teatro e classificados, o seguinte anúncio: "O BRASIL NA GUERRA. Apelo à mulher brasileira: Inscrevam-se na Cruz Vermelha Brasileira para fazer o curso de enfermeiras" (A NOITE, 1917d, p. 5).

Entende-se que o primeiro apelo tenha sido feito aos homens, ainda que pudesse estar direcionado à ideia de cidadão universal, o que explicaria o interesse de mulheres em responder a tão contundente chamado, pois o artigo dizia que a segurança da pátria estaria em risco e todos deveriam estar preparados para a sua defesa. O segundo apelo, por sua vez, está claramente direcionado às mulheres, solicitando sua participação no mesmo esforço de guerra, mas como enfermeiras.

Até então, o serviço das enfermeiras era considerado um ato de generosidade, voluntário. Segundo Mercedes Neto (2011), a crise econômica nos países europeus, gerada pela guerra, fez com que governos passassem a pagar salários para as enfermeiras profissionais, diferenciadas das voluntárias. Dessa forma, a guerra abriu o campo para a profissionalização das enfermeiras. Em 1908, a Cruz Vermelha Brasileira tornou-se ativa nos esforços de saúde pública e sanitária no Rio de 
Janeiro. Em 1916, seguindo o exemplo de outros países, a Cruz Vermelha no Rio de Janeiro e em São Paulo ampliou o recrutamento de mulheres, estabelecendo critérios de personalidade e conduta.

Entre as qualidades morais indispensáveis à enfermeira, podemos citar como primordiais as seguintes: calma, precisão, atenção, espírito de observação, regularidade, rapidez na execução, paciência, autoridade, atitude reservada e afetuosa, silêncio e cumprimento do dever profissional (NETO, 2011 , p. 54-55).

O uniforme das enfermeiras era austero e modesto, lembrava o hábito religioso das freiras. Ressaltava-se também a obediência, visto que eram subordinadas a médicos e a ordem patriarcal deveria prevalecer. Representações das enfermeiras como anjos eram parte do imaginário da propaganda de guerra. Mas, se por um lado, a campanha para a formação de enfermeiras reproduzia papéis de gênero tradicionais, por outro, ela servia como instrumento para outras reivindicações de mulheres que buscavam uma carreira profissional.

Além da profissionalização, reivindicavam mudanças no currículo escolar. Escrevendo em defesa da prática de esportes para a mulher, Esther Machado de Campos (1917) juntou a questão da guerra e a importância da saúde da mulher, apoiada num discurso de Olavo Bilac:

De uns tempos, a esta parte, é sabido, soprou sobre o paiz o frenesi da guerra. De toda parte surgem legiões e legiões de propugnadores do ensino militar, que lançam à margem a educação physica raciocinada e bem orientada. Na tribuna, na imprensa, na sociedade, no lar, em toda a parte o thema obrigatório é a guerra e a militarização do homem. A mulher, nesta agitação, em parte benéfica, é olvidada e abandonada, muito embora tendo o "pioneiro do reerguimento nacional" declarado em uma festa esportiva, que o Brasil precisa de enfermeiras.

Mas, a mulher, para ser enfermeira é preciso ser forte, ter saúde e dextreza. E isso só poderá ser conseguido com o sport bem praticado e bem orientado. [...]

É de enfermeira que precisamos... E como obte-las?

É facil... Inicie-se desde já a propaganda nas escolas, na tribuna, na imprensa, por toda parte, conduzindo a mulher ao sport raciocinado, porém, ao ar livre, em plena posse da natureza (p. 34).

A enfermeira era o contraponto da soldada. A primeira exercia um papel que era uma extensão de seu papel de mãe e cuidadora, enquanto a segunda desafiava os limites sociais e culturais impostos às mulheres ao ousar uma atuação tradicionalmente reservada aos homens. Porém, tanto a enfermeira quanto a militar - atuando nas frentes de combate ou na retaguarda precisavam ter força física e boa saúde, além de educação formal.

O debate público revelou que muitos brasileiros viam as mulheres militares como estranhas e indesejáveis, enquanto outros as consideravam corajosas, patrióticas e louváveis. Em setembro de 1917, a Revista Feminina publicou um longo artigo sobre as soldadas na Rússia, louvando seu heroísmo:

É no momento em que os soldados arremessam as armas, em que os regimentos maximilistas desertam ou capitulam, que se organiza a Legião Feminina da Morte, destinada a incutir aos homens, pelo exemplo, a coragem e o amor à Patria. São camponesas quasi incultas, professoras, medicas, enfermeiras, stenographas, mulheres de todas as condições que se agrupam sob o comando da já cérebre Bochkariova, a Joanna D'Arc russa, e pedem ao governo que as mandem para o campo de batalha, a verter $O$ sangue pela Patria e a preencher as vagas deixadas pela cobardia ou pelo desatino dos homens (REVISTA FEMININA, 1917b, p. 20).

A autora, que assinou simplesmente Iracema, parecia estar bem informada sobre os acontecimentos no distante país, a ponto de referir-se à rejeição que o batalhão feminino enfrentava nas ruas:

Um dia, finalmente, a legião parte de Petrogrado, viaja quatro dias, recebida nas estações do percurso com escárneo e zombaria. A multidão irreverente e brutal interpela as heroinas: Por que as mulheres vão combater como soldados?

Para salvar a honra da Rússia, porque vocês homens, são cobardes!

Chegam as heroínas às linhas de retaguarda, onde o quartel general as aloja em galpões de madeira, semi-enterrados no solo, onde os leitos são simples táboas pousadas na terra.

Os soldados cercam o acampamento das mulheres, atroam os ares com vaias estridentes (REVISTA FEMININA, 1917b, p. 20).

Está claro que informações mais detalhadas sobre a rejeição dos russos às mulheres militares foram censuradas pelo governo revolucionário e não chegaram ao público por décadas. Hoje sabemos que a reação de soldados e civis foi além dos meros insultos, havendo casos de violência física com espancamento e estupro. A própria Maria Bochkareva fora alvo de violência física e sexual (STOCKDALE, 2004), o mesmo tendo ocorrido a outras mulheres que participaram de batalhões militares (SHPOLBERG, 2018).

No Rio de Janeiro, as moças da Linha de Tiro Orsina da Fonseca e as candidatas a soldadas da mesma escola foram insultadas apenas verbalmente. 
Carabina no ombro, passo "ordinário" ou acelerado, exercitando-se no tiro, as recrutas tinham sua militarização. Tudo muito simplório, não levado a sério numa época em que à mulher não se permitia tais avanços, os humoristas, principalmente os caricaturistas, gozavam diariamente nos jornais e revistas o "batalhão da professora Daltro" (Jota EFEGÊ, 1981, p. 26).

No livro A Dominação Masculina, Bordieu (2016) afirma que os papéis de gênero são carregados de valores simbólicos. A virilidade, por exemplo, é uma qualidade masculina, que agrupa a capacidade reprodutiva e sexual, a sociabilidade e a aptidão para o combate e o exercício da violência, elementos encontrados também na Primeira e Segunda Guerra Mundiais e também na Guerra do Vietnã (MEYEROWITZ, 2008). A guerra, neste caso, é ao mesmo tempo uma obrigação e uma prerrogativa masculina, que define o "homem verdadeiro". Sendo assim, o homem reage com violência ao ver seu poder usurpado e sua honra atacada por mulheres que deveriam ser-lhe submissas. Na mesma linha, Michelle Perrot (1995), por sua vez, afirma que a guerra é em si um ato de virilidade que tende a consolidar os papéis tradicionais: reforçando a disciplina nos homens e alimentando sentimento de culpa nas mulheres.

Ao contrário das reações negativas à proposta de mulheres militares, as enfermeiras da Cruz Vermelha contavam com grande apoio público e governamental, pois não havia confronto com o masculino, e seu papel era o de prestar apoio e cuidado aos feridos e desabrigados pela guerra, sem desafiar a ordem hierárquica. Em 1917, Anna Rita Malheiros exaltava as qualidades femininas de paz e serenidade, e o comprometimento das mulheres para com seus filhos e maridos, ao advogar pelo alistamento na Cruz Vermelha.

Mas acima do marido, acima do irmão, acima da coberta de nossas casas, há uma imagem suprema, que se estampa, como uma Veronica no lenço branco do espaço, uma imagem que é uma bençam e pode ser uma maldição, uma imagem que tudo abrange e tudo domina, a cujo seio nos criamos, que é a concretização fecunda de um ideal, e que se chama - A Patria! [...]

Nós, as forças serenas, não podemos interromper o cyclo de nossa acção no momento em que a Patria solicita a conjugação dos esforços de todos os seus filhos para o desaggravo de seu pavilhão ultrajado.

Estão abertas as inscripções para a Cruz Vermelha Brasileira... Nossa missão continuará a ser de amor e caridade, a missão suave que no estrondo dos grandes cataclysmas, continua o seu trabalho obscuro de criação e de recomposição na intima tepidez do seio da terra... Inscrevamo-nos na Cruz Vermelha! (Anna Rita MALHEIROS, 1917a, p. 15).

Em outro artigo, a autora faz novo apelo às mulheres para apoiarem o serviço militar obrigatório, instituído pelo governo federal. O mesmo argumento de sacrifício maternal pelo bem da pátria é utilizado.

Ao espírito feminino repugna toda ou qualquer medida, que possa ser enquadrada nos actos de força ou de violência. Não somente por este prisma, que é integral ao seu temperamento, como ainda pelas considerações affectivas e presagios que the dita seu coração de esposa ou mãe, o serviço militar ao primeiro golpe de vista, choca seu espirito (MALHEIROS, 1917b, p. 11).

O texto toma uma página inteira, conclamando as mulheres a pressionarem seus filhos e maridos para se alistarem. Argumenta que a sociedade precisa desenvolver tal disciplina, e que todos precisam se desapegar de necessidades individuais e lutar pelo bem da nação. Na mesma edição, Raymunda de Souza Chevalier (1917), de Manaus, escreve elogios às integrantes dos batalhões femininos russos (retratadas em três fotografias na mesma página), expressando seu desejo de que as mulheres brasileiras pudessem também contribuir para o progresso do país (CHEVALIER, 1917, p. 25).

A resposta aos elogios de Chevalier vem de Malheiros, que faz uma dura crítica ao "grito epilético de absurda emancipação" das sufragistas inglesas, e àquelas que adotavam modismos "do mundanismo da decadência occidental", reivindicando participação mais ativa na guerra.

São escassas excepções essas, que se aproveitam do momento doloroso que atravessa nosso paiz, para brilhantemente exhibirem um falso e pouco sincero patriotismo, pedindo carabinas para combater, e lançando assim, o ridículo sobre o nosso sexo.

A brasileira digna das nossas tradições de antanho conserva-se intangida dentro do lar, na modestia que é virtude, na pureza do seu amor que é abnegação, na dedicação obscura que é o heroísmo...

Ella recebeu com serena fortaleza a notícia da guerra; não sahiu de sua casa; não se exhibiu; não fez alarde de seu patriotismo; mas de seus braços, desde logo desceu o filhinho e, como outrora, correu a levar armas a seu esposo, a seu filho e a mostrar-lhes o caminho dos quartéis, para o voluntariado.

Foi, então, e só então, quando os viu partir, que se lembrou que eles podiam ser feridos, que podiam sucumbir nos campos da refrega... Não tentou, porém, chamal-os, nem os fazer recuar em seu dever.

Um único gesto teve: foi cortar o linho para o seu primeiro avental na Cruz Vermelha Brasileira (MALHEIROS, 1917c, p. 15). 
Ao ressaltar a natureza dócil das mulheres brasileiras, a autora destacou a enfermeira da Cruz Vermelha como único papel aceitável para uma mulher respeitável na guerra, além da obrigação de encorajar o alistamento dos filhos e marido. Em fevereiro de 1918, Anna Rita mais uma vez reforçava seu argumento contra as mulheres militares, num editorial de duas páginas. Apesar de admitir que algumas mulheres poderiam apoiar o país em guerra substituindo homens nas fábricas e outras tarefas, mantinha-se energicamente contrária às soldadas:

Não falando do batalhão de mulheres russas que marcharam para a frente de batalha organização que deixamos de commentar pela ogeriza que nos causam todas as manifestações ridículas de despropositado feminismo - a mulher entre os belligerantes tornou-se, de um momento para outro um elemento de enorme efficiencia, de valor definido, como factor de victoria, substituindo o braço masculino na lavoura, no commercio e nas industrias - e, principalmente, nas industrias de guerra (MALHEIROS, 1918, p. 11-12).

A Revista Feminina reflete a opinião dividida entre as mulheres brasileiras. Algumas preocupadas com o futuro da família, posicionando-se inteiramente contra a guerra; outras tentando estabelecer um modo "decente" de apoiar a guerra, como enfermeiras, por exemplo, e outras ainda pleiteando igualdade plena, fosse para lutar nas frentes de luta no estrangeiro, fosse para cuidar da segurança da nação enquanto os homens estivessem na guerra.

No discurso das que decidiram apoiar a guerra, fosse como enfermeiras ou como militares, constata-se uma alta valorização do sacrifício e do amor à pátria. Questões de apreço à honra feminina variam: enquanto algumas identificavam a honra no cumprimento das expectativas ao papel tradicionalmente legado às mulheres, outras, como as seguidoras de Leolinda Daltro, buscavam a honra de defender a pátria, até então exclusiva dos homens.

Desde 1910 a escola Orsina da Fonseca oferecia cursos de costureiras, datilógrafas, eugenia e puericultura e um programa de educação física que incluía esgrima e tiro. Em 1917, além do treinamento militar, implementou o curso de enfermagem, reconhecido pela Cruz Vermelha Brasileira (DALTRO, 1922). Não está claro se as alunas poderiam escolher um dos cursos ou se atendiam a todos. A professora via os cursos como dois lados do engajamento das mulheres no esforço nacionalista enquanto o país se preparava para a guerra.

Em comum entre homens e mulheres que louvavam as enfermeiras e os que pleiteavam pelas soldadas, estava a preocupação com a honra da nação, que deveria ser defendida com armas, nos campos de batalha. Quando a imprensa entrevistou Leolinda sobre as mulheres e a guerra, ela explicou que suas alunas não tinham medo da guerra e estavam prontas para ir para a Europa, se necessário (DALTRO, 1922). Othon de Castilho Daltro, neto de Leolinda, declarou que certa vez ela respondeu aos insultos que os homens gritavam para suas alunas, desafiando-os: "Se vocês não honram suas calças agindo como homens e se alistando como soldados, eu e minhas alunas podemos emprestar-Ihes as nossas saias!" (apud ROCHA, 2002, p. 307). A resposta atribuída à professora demonstra uma acomodação aos estereótipos de gênero, ao tentar envergonhar os homens que resistiam ao alistamento militar.

\section{Fim das Batalhas?}

Em agosto de 1918, o Brasil enviou 1500 voluntários como parte da Divisão Naval em Operações de Guerra, a qual se incorporou à Missão Médica Especial, formada por 86 membros, entre eles cirurgiões militares, médicos e farmacêuticos voluntários, além de 15 esposas de médicos que se engajaram como enfermeiras. A missão estabeleceu-se no hospital Franco-Brasileiro em Paris até 1919 (Carlos SILVA, 2014). Meses antes do final da Grande Guerra, o debate sobre o papel da mulher no conflito bélico começou a arrefecer no Brasil, o que se deve às múltiplas crises que afetaram o país: a epidemia de gripe espanhola, que causou milhares de mortes; a geada que dizimou cafezais no sudeste; pragas de gafanhotos em 1917 e 1918 no Oeste Paulista; e a crise econômica.

Com a consolidação da Revolução Comunista na Rússia, a Legião Feminina da Morte foi desmantelada, considerada parte da ideologia imperialista. Suas integrantes foram perseguidas. As memórias das ex-combatentes e de jornalistas exaltam o heroísmo daquelas que não hesitaram em defender seus companheiros e companheiras, muitas caindo em combate. Há também evidências de represálias contra as soldadas, aprisionadas e torturadas pelos bolcheviques entre 1917 e 1920. Os homens russos viram como traição a entrada de mulheres em frentes de combates no momento em que a propaganda revolucionária convocava os homens à deserção. Os bolcheviques, em especial, as viram como parte do plano do czar de envergonhar os soldados que se recusavam a lutar por razões políticas, chamando-os de covardes, e humilhando-os ao substituí-los por mulheres. Maria Bochkareva foi aprisionada e executada em 1920 pelo exército bolchevique (SHPOLBERG, 2018).

Na Revista Feminina, o debate sobre o voto feminino em diferentes países ocupou as edições no ano de 1919, incluindo a vitória das sufragistas nos Estados Unidos. O Presidente Woodrow Wilson reconheceu, ao fim da Grande Guerra, o valor da contribuição das mulheres. Falando ao 
Congresso, ele exaltou as enfermeiras e o apoio daquelas que assumiram papéis vitais na indústria, nos transportes, no comércio, nas comunicações e na lavoura, que levaram à vitória aliada. Em 1919, o Presidente Wilson propôs a emenda constitucional que garantiria o voto às mulheres daquele país.

Nós fizemos das mulheres, nossas parceiras nesta guerra. Deveríamos admiti-las como parceiras no sofrimento e sacrifício e labuta, e não como parceiras em privilégios e direitos? Esta guerra não poderia ter sido travada [...] se não tivesse sido pelos serviços das mulheres, serviços prestados em todas as esferas, não apenas nos campos de esforços nos quais estamos acostumados a vê-las trabalhar, mas onde quer que os homens trabalhassem e sobre as próprias bordas dos campos de batalha em si (HANSEN, 2017). ${ }^{3}$

Apesar de haverem conquistado o direito ao voto, setores da sociedade pressionaram para que as mulheres americanas (e europeias) retornassem a seus lares e a seus limitados papéis de gênero, numa tentativa de recompor a ordem social nos padrões que vigoravam antes da guerra. Muitas perderam suas posições de trabalho, mas alguns avanços permaneceram, influenciando a plataforma das reivindicações pelos direitos das mulheres nas décadas seguintes. mulheres:

As palavras escritas por Iracema, na Revista Feminina em 1917, sintetizavam a luta das

Não será, certamente com o seu exemplo heroico, e com o seu sacrifício que a humanidade se approximará dos ideaes pacíficos. Mas não deixa de ser symptomatica a concessão dada às mulheres russas para se baterem na guerra, quando em quase todas as nações do mundo ainda se negam à mulher os direitos pacíficos do voto. Quem nos diria que a mulher eleitora seria antecipada pela mulher guerreira? (REVISTA FEMININA, 1917b, p. 20).

A conquista feminina do direito de voto nos Estados Unidos e o discurso do presidente daquele país reconhecendo o valor das mulheres reforçaram a retórica das sufragistas brasileiras, que a esta altura já vinham angariando simpatias entre intelectuais e políticos.

Em 11 de julho de 1919, o Jornal do Brasil informava que o Ministro da Guerra autorizara o desenvolvimento da instrução militar, sob a supervisão do exército, para as alunas da Escola Orsina da Fonseca, por compreender os esforços que a mesma fazia para propiciar "uma educação completa" às mulheres. A notícia dizia que o plano da professora Daltro era levar seu batalhão para participar da recepção ao recém-eleito Presidente Epitácio Pessoa, junto com as tropas regulares (JORNAL DO BRASIL, 1 1/07/19, p. 6). O "Batalhão Feminino" - agora renomeado "Legião da Paz" e ocupando o Arsenal da Marinha para exercícios militares práticos - se apresentou uniformizado para a Recepção Presidencial em 21 de julho de 1919, empunhando bandeiras brancas ao invés de carabinas (JORNAL DO BRASIL, 21/07/19, p. 1).

No mês seguinte, o mesmo jornal apresentou, na coluna "Foro", a notícia de que Leolinda Daltro tivera recurso julgado pela Junta Eleitoral Federal, para um requerimento apresentado ao juiz de direito da Vara Cível, solicitando seu registro como eleitora. Tendo sido negada naquela instância, ela entrou com recurso no órgão superior, que novamente negara seu requerimento, sob o argumento reproduzido em parte no jornal:

A Junta Eleitoral de Recursos, depois de visto e devidamente examinado, nega provimento ao recurso para confirmar a decisão recorrida. Ao projecto do nosso Estatuto Fundamental foram apresentadas diversas emendas atribuindo o direito de voto às mulheres e o Poder Constituinte as rejeitou todas depois de ampla discussão que consta dos Annaes, por entender-se a medida inconveniente à ordem pública e social (JORNAL DO BRASIL, 23/08/19, p. 9).

As "diversas emendas" apresentadas para aprovação do voto às mulheres refletiam uma amplificação da campanha das sufragistas, com novas vozes e personagens, como a feminista Bertha Lutz, jovem da elite que acabara de chegar de Paris.

Já as enfermeiras da Cruz Vermelha poderiam dizer que alcançaram certo avanço em relação ao reconhecimento e ao apoio que receberam tanto da sociedade em geral quanto do poder público. A conquista da profissionalização abriu um novo campo de trabalho para as mulheres, enquanto que as ações das enfermeiras voluntárias mostraram-se vitais no enfrentamento de epidemias como a da gripe espanhola.

A memória da Legião Feminina da Morte apagou-se rapidamente, e o discurso em defesa dos direitos de mulheres exercerem papéis militares ativos no Brasil calou-se por décadas. As brasileiras esperaram mais de oitenta anos para serem aceitas no Exército como soldadas.

Afinal, todos os lados do debate sobre a participação da mulher na Primeira Guerra Mundial - o das que pregavam o apoio logístico, o das que se apresentavam como enfermeiras voluntárias ou profissionais, o das que pleiteavam igualdade nos campos de batalha - reivindicavam basicamente a mesma coisa, o direito à cidadania plena e à honra cívica.

\footnotetext{
${ }^{3}$ Tradução da autora.
} 
Acima de tudo, prevaleceu o discurso sobre a mulher-enfermeira de Malheiros: mulher terna, delicada e pronta ao sacrifício. Essa retórica, que dominaria a imprensa e a cultura popular por várias décadas, contribuiu para evitar qualquer "inconveniente à ordem pública e social", parafraseando o argumento do Juiz em 1919. O que poucos sabiam era que Anna Rita Malheiros era o pseudônimo de Claudio de Souza, médico e escritor, irmão da fundadora da Revista Feminina e seu assíduo contribuinte (Neide BARROS, 2014). Sua opinião não refletia o pensamento conservador de certas mulheres educadas, como fazia crer, mas uma visão masculina da ordem social e da diferenciação dos papéis de gênero na guerra: homens para matar e mulheres para cuidar.

\section{Referências}

A NOITE. "O Partido Republicano Feminino vae entrar em acção". A noite, Rio de Janeiro, 11/1 1/ 1917a. p. 1.

A NOITE. "Todos pela Pátria". A noite, 06/11/1917b, p. 1.

A NOITE. "O que os brasileiros devem fazer em todo o país". A noite, 07/1 1/1917c, p. 1.

A NOITE. "O Brasil na Guerra". A noite, 09/1 1/1917d, p. 5.

BADINTER, Elisabeth. Um amor conquistado: o mito do amor materno. Rio de Janeiro: Nova Fronteira, 1985.

BARROS, Neide Ferreira. "A visibilidade feminina através da fala de Anna Rita Malheiros na Primeira República Brasileira". In: XVI ENCONTRO DE HISTÓRIA REGIONAL, ANPUH-Rio, Anais... 2014. Disponível em http://www.encontro2014.rj.anpuh.org/resources/anais/28/1400156808_ARQUIVO_Avisibilidade femininaatravesdafaladeAnnaRitaMalheiros-NeideCeliaFerreiraBarros.pdf. Ácesso em 29/07/2018.

BOURDIEU, Pierre. A dominação masculina. A condição feminina e a violência simbólica. Rio de Janeiro: BestBolso, 2016.

BRAGA, Valterian Mendonça. A experiência estratégica brasileira na Primeira Guerra Mundial, 1914-1918. 2008. Dissertação (Mestrado em Ciência Política) - Universidade Federal Fluminense, Niterói.

BUITONI, Dulcília. Mulher de papel. A representação da mulher pela imprensa brasileira. São Paulo: Loyola, 1981.

CAMPOS, Esther Machado. "Educação physica da mulher". Revista Feminina, n. 38, p. 34, julho 1917.

CARVALHO, José Murilo de. "As Forças Armadas na Primeira República: o poder desestabilizador". In: FAUSTO, Boris. História Geral da Civilização Brasileira, O Brasil Republicano, v. 2, 5. ed. Rio de Janeiro: Bertrand Brasil, 1997. p. 181-234.

CHEVALIER, Raymunda de Souza. "A Mulher na Guerra". Revista Feminina, n. 42, p. 25, novembro 1917.

CLARO, Livia. "Pensando a guerra e a nação: a Liga Brasileira pelos aliados e suas ideias sobre o Brasil no contexto da Primeira Guerra Mundial (1915-1919)". História: Debates e Tendências, v. 14, n. 2, p. 292-305, jul./dez. 2014.

DALTRO, Leolinda de Figueiredo. Início do feminismo no Brasil - Subsídios para a história. Rio de Janeiro: Typ. Orsina da Fonseca, 1922.

DOURADO, Maria Teresa Garritano. A história esquecida da Guerra do Paraguai: fome, doenças e penalidades. 2010. Dissertação (Mestrado em História Social) - Universidade de São Paulo, São Paulo.

ELSHTAIN, Jean. "Preface". In: ELSHTAIN, Jean Bethke; TOBIAS, Sheila (Eds.). Women, Militarism, and War: Essays in History, Politics and Social Theory. Savage: Rowman \& Littlefield, 1990. p. IX-XII.

EFEGÊ, Jota. "Antes das mulheres 'marinheiras' tivemos um batalhão feminino”. O Globo, 08/08/ 1981 , p. 26.

FONSECA, Claudia. "Ser mulher, mãe e pobre". In: DEL PRIORE, Mary (Org.). História das Mulheres no Brasil. São Paulo: EDUNESP/Contexto, 1997. p. 510-553. 
HAHNER, June. A mulher brasileira e suas lutas sociais e políticas 1850-1937. São Paulo: Brasiliense, 1981.

HANSEN, Lauren. "The women of World War l”. The Week, abril 201 7. Disponível em http://theweek.com/ captured/690302/women-world-war. Acesso em 29/07/2018.

JORNAL DO BRASIL. "Escola Orsina da Fonseca - Instrucção Militar às Alunas". Jornal do Brasil, 11 / 07/1919, p. 6.

JORNAL DO BRASIL. "O Batalhão Feminino". Jornal do Brasil, 21/07/1919, p. 1.

JORNAL DO BRASIL. "Foro". Jornal do Brasil, 23/08/1919, p. 9.

LEAL, Ranielle; REGO, Ana Regina. "Imprensa brasileira na Primeira Guerra Mundial, intelectuais em ação”. In: 10 ENCONTRO NACIONAL DE HISTÓRIA DA MÍDIA, 2015. Disponível em http://www.ufrgs.br/ alcar/encontros-nacionais-1/encontros-nacionais/10o-encontro-2015/gt-historia-da-midiaimpressa/imprensa-brasileira-na-primeira-guerra-mundial-intelectuais-em-acao/view. Acesso em 20/07/2018.

LIMA, Raquel Sousa; TEIXEIRA, Igor Salomão. "Ser mãe: o amor materno no discurso católico do século XIX”. Horizonte, v. 6, n. 12, p. 113-126, jun. 2008.

MALHEIROS, Anna Rita. "A Cruz Vermelha Brasileira". Revista Feminina, n. 37, p. 15, junho 1917 a.

MALHEIROS, Anna Rita. "Novembro". Revista Feminina, n. 42, p. 11, novembro 191 7b.

MALHEIROS, Anna Rita. "A Mulher Brasileira na Guerra". Revista Feminina, n. 43, p. 15, dezembro $1917 \mathrm{C}$.

MALHEIROS, Anna Rita. "A Mulher Brasileira na Guerra". Revista Feminina, n. 45, p. 1 1-12, fevereiro 1918.

MEYER, Gerald J. A world undone. The story of the Great War. New York: Random House, 2006.

MEYEROWITZ, Joanne. "A history of gender". The American Historical Review, v. 113, n. 5, p. 13461356, 2008.

MORSELLI, Francesca; LEHMANN, Jörg. "Women During the First World War". CENDARI Archival Research Guide, 2016. Disponível em https://hal.archives-ouvertes.fr/hal-01419144/document. Acesso em 13/07/2018.

MOUGEL, Nadege. "World War Casualties". Reperes. Partenariat Educatif Grundtvig, 2009-201 1. Disponível em https://www.census.gov/history/pdf/reperes 11201 8.pdf. Acesso em 12/1 1/2018.

NETO, Mercedes. A produção na crença da imagem da enfermeira da Cruz Vermelha no período da Primeira Guerra Mundial (1917-1918). 2011. Dissertação (Mestrado em Enfermagem) Universidade Federal do Rio de Janeiro, Rio de Janeiro.

PASSOS, Elizete. De anjos a mulheres. Ideologias e valores na formação de enfermeiras. Salvador: EDUFBA, 2012.

PERROT, Michelle. "Stepping out". In: DUBY, Georges; PERROT, Michelle (Eds.). A History of women: emerging feminism from Revolution to World War. London: Belknap/Harvard, 1995. p. 449-481.

PORTO, Fernando; ATAIDE, Anna Paula; VILELLA, Débora; RIBEIRO, Marina. "Fantasia de Enfermeira no Carnaval do Rio de Janeiro (1916)". DocPlayer, Rio de Janeiro, LACENF/UNIRIO, 2014. Disponível em http://docplayer.com.br/7285147-Fantasia-de-enfermeira-no-carnaval-do-rio-de-janeiro1916.html. Acesso em 12/07/2018.

REVISTA FEMININA. "O exército feminino na Guerra". Revista Feminina, n. 43, p. 56, 22/12/1917a.

REVISTA FEMININA. "A Legião Feminina da Morte". Revista Feminina, n. 40, p. 20, setembro $1917 \mathrm{~b}$.

ROCHA, Elaine. Entre a pena e a espada: A trajetória de Leolinda Daltro (1859-1935). 2002. Tese (Doutorado) - FFLCH, Universidade de São Paulo, São Paulo.

ROCHA, Elaine. "Vida de professora: ideias e aventuras de Leolinda de Figueiredo Daltro durante a Primeira República". Mundos do Trabalho, v. 8, n. 15, p. 29-47, 2016. 
SALAS, Elizabeth. Soldaderas in the Mexican military: myth and history. Austin: University of Texas Press, 1990.

SCOIT, Joan. "Gender, a useful category of historical analysis". The American Historical Review, v. 91, n. 5, p. 1053-1075, 1986.

SCHULTZ, Jane. Women at the Front: Hospital Workers in Civil War America. Greensboro: UNC Press, 2007.

SHPOLBERG, Angela. "Women journalists and the Women's Batallion of Death". LARB, March 23, 2018. Disponível em https://lareviewofbooks.org/article/women-with-the-gun-maria-bochkarevaand-the-womens-battalion-of-death/\#_ftn4. Acesso em 22/07/201 8.

SILVA, Carlos Edson. "A Missão Médica Especial brasileira de caráter militar na Primeira Guerra Mundial". Navigator, n. 20, p. 94-108, 2014. Disponível em http://revistanavigator.com.br/navig20/ art/N20_art2.pdf. Acesso em 29/09/2018.

SOIHET, Rachel. Condição feminina e formas de violência: mulheres pobres e violência urbana. Rio de Janeiro: Forense Universitária, 1989.

SOWERS, Susan. Women combatants in World War I: A Russian case study. Research Project. Pensylvania: USA Army War College, 2003.

STOCKDALE, Melissa. “'My Death for the Motherland Is Happiness': Women, Patriotism, and Soldiering in Russia's Great War, 1914-1917". The American Historical Review, v. 109, n. 1, 2004. Disponível em https://academic.oup.com/ahr/article-abstract/109/1/78/108945. Acesso em 19/07/2018.

TRINDADE, Etelvina Maria. Clotildes ou Marias. Mulheres de Curitiba na Primeira República. Curitiba: Fundação Cultural de Curitiba, 1996.

Elaine Pereira Rocha (elaine.rocha@cavehill.uwi.edu) é licenciada em História (UNITAU); mestre em História (PUC-SP); mestre em História Cultural (UP África do Sul) e doutora em História Social (USP). Principais livros publicados: Milton Gonçalves: Memórias históricas de um ator afro-brasileiro (2019); Another Black Like Me (com Nielson Bezerra, 2015); Racism in Novels: a Comparative Study of Brazilian and South African Cultural History (2010); Saci Pererê, O Vento da Liberdade (2000).

\section{COMO CITAR ESSE ARTIGO DE ACORDO COM AS NORMAS DA REVISTA}

ROCHA, Elaine Pereira. "Guerreiras ou Anjos? As Mulheres Brasileiras e a Grande Guerra". Revista Estudos Feministas, Florianópolis, v. 28, n. 3, e61492, 2020.

CONTRIBUIÇÃO DE AUTORIA

Não se aplica.

FINANCIAMENTO

Não se aplica.

CONSENTIMENTO DE USO DE IMAGEM

Não se aplica.

APROVAÇÃO DE COMITÊ DE ÉTICA EM PESQUISA

Não se aplica.

CONFLITO DE INTERESSES

Não se aplica.

LICENÇA DE USO

Este artigo está licenciado sob a Licença Creative Commons CC-BY International. Com essa licença você pode compartilhar, adaptar, criar para qualquer fim, desde que atribua a autoria da obra. 


\section{HISTÓRICO}

Recebido em 11/02/2019

Reapresentado em 11/07/2019

Aprovado em 29/11/2019 